\title{
Desain Produk Kemasan Cokelat dengan Menggunakan Peran Elemen Fungsional Desain
}

\author{
Yosef Richo \\ Program Studi: Desain Produk, Fakultas Teknik Informatika, \\ Institut Bisnis dan Informatika Stikom Surabaya \\ Email: yosef@stikom.edu
}

\begin{abstract}
Abstrak - Industri cokelat menjadi bisnis yang sangat berpotensi baik secara global maupun lokal(Indonesia) karena cokelat adalah jenis produk makanan ringan yang paling diminati secara oleh konsumennya saat ini dan yang berikutnya adalah Indonesia adalah penghasil cokelat terbesar ketiga didunia saat ini. Adalah tepat bagi para creativepreuner untuk mencoba menilik industri cokelat ini, dan salah satu peran penting bagi aspek peningkatan penjualan produk cokelat adalah dari desain produk kemasannya, maka dalam artikel ini akan menjelaskan lebih lanjut terkait strategi bagi para desainer dalam mendesain sebuah kemasan yang diharapkan dapat membantu menarik minat pembelian konsumen, ada beberapa atribut elemen desain secara fungsional didalam kemasan yakni elemen bentuk, ukuran dan material, hasil koletif data dapat dari responden akan diaplikasikan dalam proses mendesain dengan metode RDE atau mendesain dengan menggunakan bantuan teknologi pada sebuah kemasan cokelat.
\end{abstract}

Kata kunci: cokelat, kemasan, dan elemen fungsional desain

Abstract - The Industrial Chocolate becomes a very potential business both for global and local (Indonesia) because chocolate is the most popular snack product at globally by its current consumers also Indonesia is the third largest chocolate producer in the world until now. It is appropriate for the creativepreuner to try to look at this industry, and one of the important roles for the increasing aspect of chocolate product sales is from the design packaging products, so in this article it will explain more about the strategy for the designers when to try designing a packaging that have to expected help attracting consumer purchases, there are some functional design element attributes elements inside at the packaging: form, sizes and materials. The data is collected from respondents will be applied in the process of designing packaging product with the RDE method or designing using the technology.

Keywords: chocolate, packaging, and design functional element

\section{PENDAHULUAN}

Cokelat adalah jenis produk low involvement dimana dalam proses pembeliannya konsumen lebih mengarah pada aspek affektif (nilai emosional) didalamnya, namun cokelat juga dikategorikan sebagai produk yang sifatnya dapat dengan cepat mempengaruhi niat pembelian ketika pertama kali melihatnya terutama pada pengaruh desain kemasannya [1]. Dengan demikian cokelat digunakan dalam penelitian ini karena kemudahan dalam proses stimuli kepada konsumen pada tahap awal pembelian (prepurchase) dan eksperimen yang akan dilakukan nantinya.

Menurut laporan tahunan ICCO atau International Cocoa Organization (2010), disebutkan bahwa Indonesia adalah negara ketiga terbesar didunia penghasil cokelat dengan jumlah ratarata 535.000 ton per tahun setelah Pantai gading 1.242.000 ton per tahun, dan Ghana 632.000 ton per tahunnya. Selanjutnya potensi ccokelat secara global didapatkan berdasarkan data statistik dari website himpunan pengusaha cokelat secara global (chocolateforcf.org).

Diperoleh informasi bahwa:

1. Lebih dari 4,6 miliar ton, cokelat diproduksi diseluruh dunia tiap tahunnya dan Indonesia adalah Negara ketiga terbesar didunia penghasil cokelat setelah Afrika Selatan dan Ghana dan Produksi cokelat terus meningkat 4x lipat sejak tahun 1961-2015.

2. Amerika, Jerman dan Prancis menjadi Negara yang paling banyak mengimport cokelat dengan total sekitar 2 miliar dolar tiap tahunnya.

3. 10 Top Brand snack cokelat yang paling banyak dijual secara global, tidak ada satupun produk yang berasal dari Indonesia. Maka dapat diketahui bahwa sebenarnya industri cokelat sangat berpotensi, karena Sumber Daya Alam cokelat di Indonesia melimpah. Namun sayangnya, Indonesia sebagai negara penghasil dan eksportir bahan baku cokelat ketiga terbesar didunia bertolak belakang dengan kualitas brand produk lokalnya, lalu yang jadi pertanyaan atribut apa yang dibutuhkan nantinya agar membuat produk cokelat lokal diminati konsumen?

\section{Peran Kemasan pada Produk Snack Cokelat}

Kemasan adalah atribut terluar dari produk atau berguna sebagai memiliki fungsi fungsionalitas sebagai pelindung dan pembungkus dan nilai estetika sebagai identitas produk atau brand didalamnya [2]. Kemasan dapat menarik perhatian meningkatkan image dan mempengaruhi persepsi konsumen terhadap produk [3].

Kemasan dapat juga digunakan sebagai penunjang promosi perusahaan, yakni kemasan harusnya dibuat sebagai sesuatu yang menarik, karena kemasan merupakan kunci komunikasi produk dengan konsumen dan karakteristik bentuk eksisting dari kemasan tergantung dari desain dan teknologi yang digunakan didalamnya, juga tergantung pada pengaruh isu-isu yang berkembang pada masyarakat disekitarnya [4].

\section{Elemen Desain Kemasan}

Dijelaskan secara holistik bahwa terdapat banyak sekali elemen yang membentuk karakteristik desain pada kemasan, yaitu lebih dari 160 stimuli elemen didalamnya [5]. Selanjutnya lebih dispesifikkan lagi menjadi hanya 62 elemen yang selanjutnya dikategorisasikan lagi menjadi delapan kriteria untuk dijadikan sebagai dasar pengukuran variabelnya, dimana secara garis besar hal tersebut didapatkan setelah melakukan asosiasi dengan 125 profesional desainer diberbagai industri kemasan produk.

Jika dilihat dari konteks tersebut, maka sangatlah rumit bagi peneliti untuk menjelaskan kriteria kararteristik desain kemasan dengan ringkas jika implikasi tujuan pengembangan desain kemasan berdasar dari kebutuhan perusahaan dengan 
professional desainernya. Dijelaskan secara lebih spesifik untuk kemasan pada produk cokelat yang dapat dibagi menjadi beberapa kategori elemen berdasarkan visual yang terdiri dari: ukuran, grafis, material, desain produk, dan warna, sedangkan verbal elemen yang terdiri dari: Informasi produk dan informasi nutrisi dimana dapat berkorelasi dalam membentuk perilaku pembelian konsumen [6], seperti dapat dilihat pada Gambar 1.

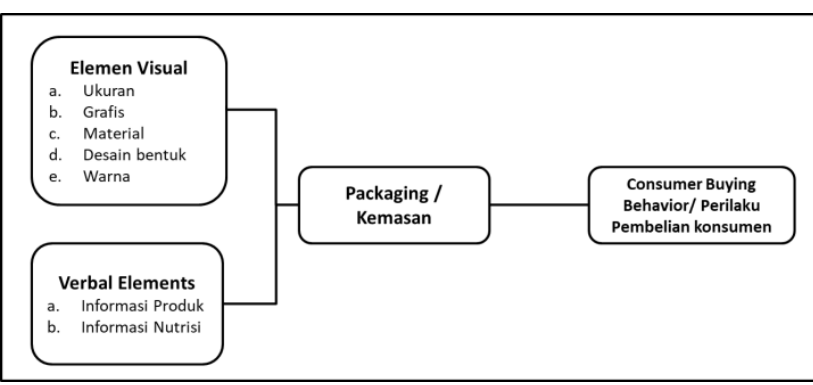

Gambar 1. Contoh elemen kemasan cokelat secara keseluruhan [6]

Hal senada dipaparkan oleh beberapa praktisi dan peneliti yang menyebutkan bahwa elemen dari desain nilai fungsional atau struktur adalah bagian awal yang penting dalam mempengaruhi komposisi dari desain selanjutnya seperti visual kemasan, indikator elemen fungsional pada kemasan tersebut dapat dilihat pada Tabel 1 [7, 8 dan 9].

Tabel 1: Contoh elemen dan faktor elemen fungsional kemasan

\begin{tabular}{|c|l|l|l|}
\hline No & $\begin{array}{l}\text { Elemen } \\
\text { Fungsional }\end{array}$ & $\begin{array}{l}\text { Faktor Elemen Fungsional / Struktur } \\
\text { dalam kemasan }\end{array}$ \\
\hline 1 & $\begin{array}{l}\text { Shape / } \\
\text { Bentuk/ } \\
\text { Desain } \\
\text { Produk }\end{array}$ & $\begin{array}{l}\text { a. Bentuk Kemasan yang menarik } \\
\text { perhatian. } \\
\text { b. Bentuk Kemasan yang mudah untuk } \\
\text { diletakkan. } \\
\text { c. Bentuk Kemasan yang nyaman untuk } \\
\text { dibawa/ dipegang. }\end{array}$ \\
\hline 2 & $\begin{array}{l}\text { Material / } \\
\text { Bahan }\end{array}$ & $\begin{array}{l}\text { a. Material yang menarik perhatian. } \\
\text { b. Material yang unik dibandingkan } \\
\text { brand yang lain. } \\
\text { c. Material eco-friendliness } \\
\text { lingkungan). } \\
\text { d. Material yang merekfeksikan kualitas } \\
\text { yang bagus. }\end{array}$ \\
\hline 3 & Ukuran & $\begin{array}{l}\text { a. Ukuran kemasan yang sesuai dengan } \\
\text { kebutuhan konsumen } \\
\text { b. Ukuran kemasan yang dapat memicu } \\
\text { niat pembelian } \\
\text { c. Ukuran kemasan yang mudah dibawa. }\end{array}$ \\
\hline
\end{tabular}

Dalam hal ini peneliti mencoba fokus pada melihat pengaruh nilai fungsionalitas desain pada kemasan cokelat untuk produk lokal sesuai dengan hasil terapan dari studi yang terdahulu. Dari dasar observasi diatas maka dapat diketahui bahwa elemen fungsionalitas pada desain kemasan sangat berpengaruh pada niat pembelian konsumen.

\section{METODE PENELITIAN}

Desain penelitian yang digunakan ialah desain penelitian dan pengembangan RDE (Rule Developing Experimentation) Pengembangan desain berdasarkan penilaian dari atribut terpilih dari beberapa alternative yang ada.Diharapkan penilaian yang dihasilkan dapat digunakan sebagai evaluasi dalam memilih desain dari alternative komponen.Goftman dan Moskowitz [8]menjelaskan bahwa penelitian pengembangan sering dikenal dengan RDE adalah metode penelitian yang digunakan untuk menghasilkan produk tertentu berdasarkan penilaian dari sudut desainer, dikarenakan desainer dirasa sudah cukup mampu menilai atribut dasar dan kesesuaian komposisi sebuah desain dan berguna untuk menguji keefektifan produk tersebut.

Metode RDE digunakan dalam penelitian ini untuk mencari kebutuhan awal terhadap desain kemasan cokelat berdasarkan penilaian dari desainer atau peneliti dari atribut-atribut yang ada agar dapat menemukan bentukan desain dengan cara yang lebih praktis.

Selanjutnya adalah menggunakan metode FGD (Focus Group Disscusion)untuk efisiensi evaluasi pengambilan data menurut Boateng[8], yaitu dengan mengumpulkan responden dari kategori kelompok yang sama atau yang diharapkan sesuai dengan kebutuhan peneliti, kemudia melakukan kuisioner langsung kepada grup responden untuk mengetahui pendapat dari desain yang diharapkan. Kemudian dilakukan penghitungan hasil kuisioner dengan metode kuantitatif untuk penilaian agar hasil dari survey dapat terintegrasi hasilnya secara satuan angka ataupun secara presentase.Dengan begitu maka diharapkan mendapatkan hasil yang valid terhadap penilaian konsumen terhadap desain cokelat.

FGD diikuti oleh 31 orang mahasiswa yang berusia antara 20-35 tahun, dengan asumsi pada usia tersebut adalah seseorang dalam tahap usia produktif, memiliki kreatifitas yang tinggi dan memiliki ketertarikan besar pada produk cokelat. Disamping itu mahasiswa yang dipilih adalah berasal dari jurusan atau program studi desain sehingga diharapkan mampu memahami dan membayangkan perkiraan arah penelitian (Gambar 2).

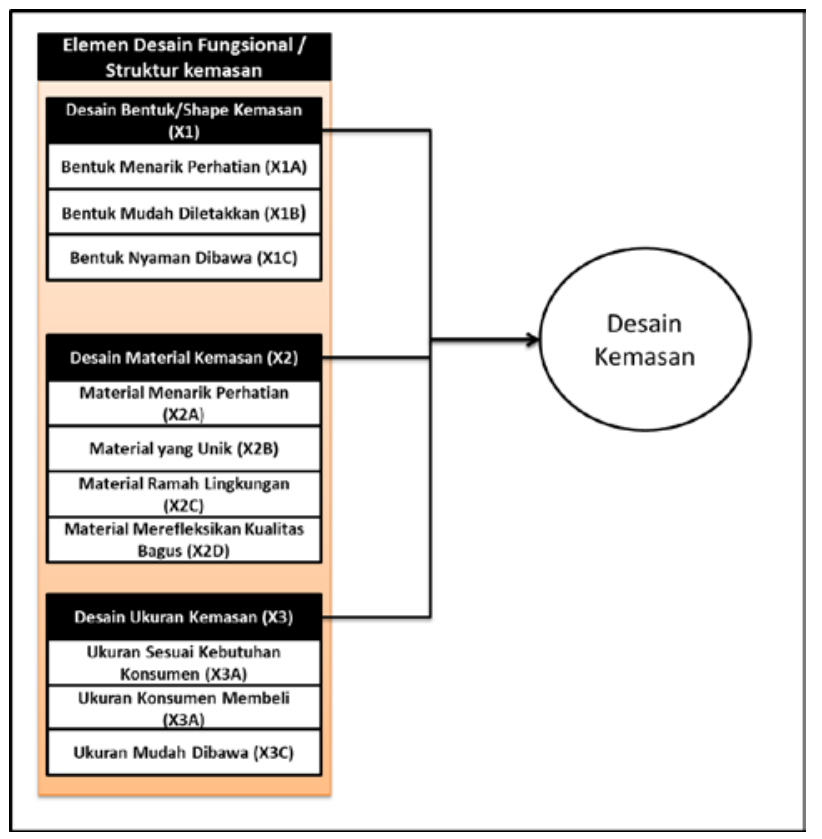

Gambar 2 Kerangka penelitian

\section{HASIL DAN PEMBAHASAN}

Setelah melakukan analisa internal untuk memilih atribut dari elemen yang akan diuji kepada responden, maka peneliti melakukan FGD dengan memberikan tahapan pertanyaan kualitatif kepada responden, responden yang akan dipilih adalah sebanyak 30 orang dengan asumsi dari Hair, Black dan Babin[9]yang menyebutkan bahwa minimal uji kelayakan data adalah sebanyak 30 orang. Responden. FGD yang dilakukan 


\section{Yosef Richo}

\section{Desain Produk Kemasan Cokelat dengan Menggunakan Peran Elemen Fungsional Desain}

bertujuan untuk memilih elemen desain yang telah terpilih dari proses seleksi internal yang untuk kemudian hasil nya dapat dinilai secara kuantitatif dengan menggunakan skala likert sebagai pembanding, dan selanjutnya hasil FGD dapat digunakan untuk menentukan arah perancangan desain secara RDE dimana elemen desain yang terpilih disatukan pada desain baru sehingga membentuk new product development pada kemasan cokelat nantinya (Gambar 3). Tabel 2 menjelaskan hasil pengolahan FGD: Elemen deasain kemasan.

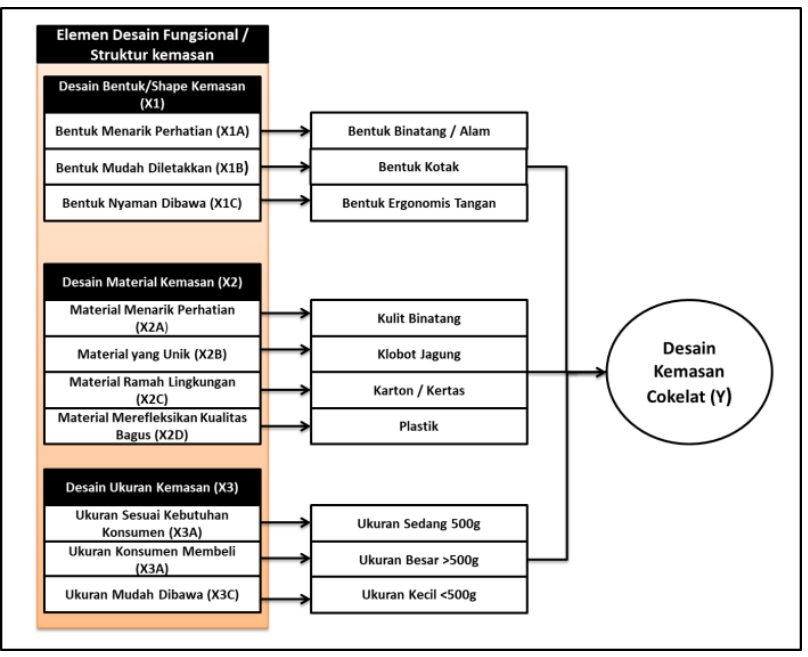

Gambar 3 Macam kategori elemen fungsional

Tabel 2 : Hasil pengolahan FGD: Elemen desain kemasan

\begin{tabular}{|c|c|}
\hline Total Responden & 31 orang \\
\hline $\begin{array}{l}\text { Jenis kelamin } \\
\text { responden }\end{array}$ & $\begin{array}{l}\text { Laki- laki }=22 \text { orang }(22,7 \%) \\
\text { Perempuan }=9 \text { orang }(9,29 \%)\end{array}$ \\
\hline Usia responden & $\begin{array}{l}31 \text { responden }=>17 \text { tahun }-<30 \text { tahun } \\
(100 \% \text { usia produktif })\end{array}$ \\
\hline $\begin{array}{l}\text { Responden } \\
\text { menyukai makan } \\
\text { cokelat }\end{array}$ & $\begin{array}{l}31 \text { responden }=31 \text { orang suka }(100 \%) \text {, } \\
0 \text { orang tidak suka }(0 \%)\end{array}$ \\
\hline $\begin{array}{l}\text { Presentase rata- } \\
\text { rata responden } \\
\text { memakan } \\
\text { cokelat dalam } 1 \\
\text { bulan }\end{array}$ & $\begin{array}{l}\text { a. } 16 \text { Responden = Sangat Jarang }(1 \mathrm{x} \\
\text { sebulan) } \\
\text { b. } 8 \text { Responden = Jarang (1-3x sebulan) } \\
\text { c. } 6 \text { responden = cukup (3-5x sebulan) } \\
\text { d. } 1 \text { responden = cukup (5-10x sebulan) } \\
\text { e. } 0 \text { responden = Sangat banyak }(>10 \mathrm{x} \\
\text { sebulan) } \\
\text { Total = } 31 \text { Responden }\end{array}$ \\
\hline
\end{tabular}

Tabel 2 : Hasil pengolahan FGD: Elemen desain kemasan (Lanjutan 1)

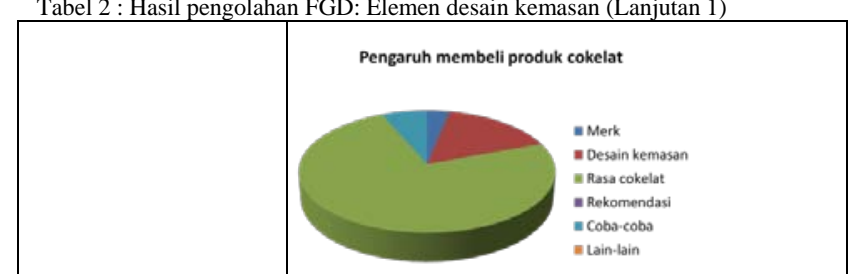

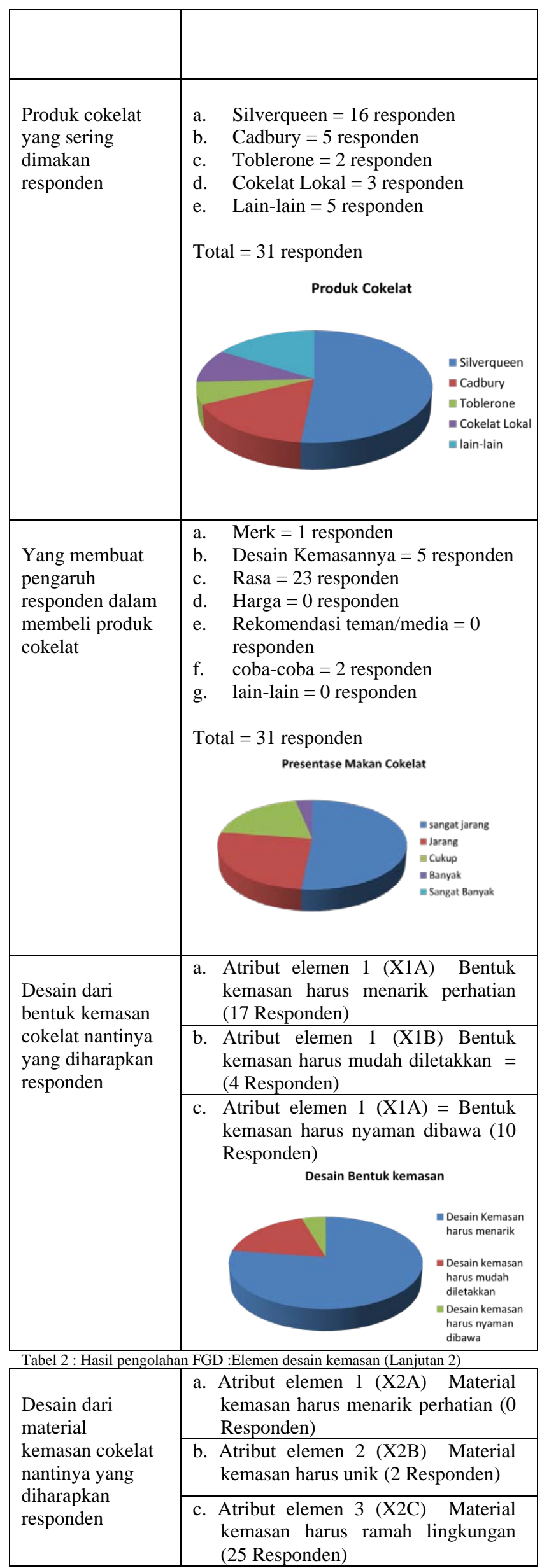




\begin{tabular}{|c|c|}
\hline & $\begin{array}{l}\text { d. Atribut elemen } 4 \text { (X2D) Material } \\
\text { kemasan harus merefleksikan } \\
\text { kualitas yang bagus (4 Responden) }\end{array}$ \\
\hline & $\begin{array}{l}\text { Material desain kemasan } \\
\qquad \begin{array}{c}- \text { Material Kemasan } \\
\text { harus menarik } \\
\text { perhatian } \\
- \text { Material Kemasan } \\
\text { harus unik } \\
- \text { Material Kemasan } \\
\text { harus samah } \\
\text { lingkungan } \\
=\text { Material Kemasan } \\
\text { harus merefeleksikan } \\
\text { kualitas yang bagus }\end{array} \\
\end{array}$ \\
\hline \multirow{4}{*}{$\begin{array}{l}\text { Desain dari } \\
\text { ukuran kemasan } \\
\text { cokelat nantinya } \\
\text { yang diharapkan } \\
\text { responden. }\end{array}$} & $\begin{array}{l}\text { a. Atribut elemen } 1 \text { (X3A) ukuran } \\
\text { kemasan harus sesuai dengan } \\
\text { kebutuhan konsumen (23 } \\
\text { Responden) }\end{array}$ \\
\hline & $\begin{array}{l}\text { b. Atribut elemen 2 (X3B) ukuran } \\
\text { kemasan harus dapat memicu } \\
\text { konsumen membelinya (5 } \\
\text { Responden) }\end{array}$ \\
\hline & $\begin{array}{l}\text { c. Atribut elemen 3 (X3C) ukuran } \\
\text { kemasan harus mudah dibawa } \\
\text { konsumen (3 Responden) }\end{array}$ \\
\hline & $\begin{array}{l}\text { (X3A) ukuran } \\
\text { kemasan harus sesuai } \\
\text { dengan kebutuhan } \\
\text { konsumen } \\
\text { (X3B) ukuran } \\
\text { kemasan harus dapat } \\
\text { memicu konsumen } \\
\text { membelinya } \\
\text { (X3c) ukuran } \\
\text { kemasan harus mudah } \\
\text { dibawa konsumen }\end{array}$ \\
\hline
\end{tabular}

Dari hasil penilaian komulatif diatas didapat beberapa hal yakni:

1. Untuk kategori usia responden dalam usia produktif 17-35 tahun, didapatkan hasil adalah $100 \%$ atau keseluruhan menyukai produk cokelat.

2. Responden rata-rata memakan cokelat dalam 1 bulan terbanyak adalah $1 \mathrm{x}$ sebulan dan kedua adalah 2-3x sebulan, hal ini menunjukkan meskipun responden menyukai produk cokelat namun tidak banyak mengkonsumsi dalam skala yang banyak.

3. Responden menyukai atau berminat membeli produk cokelat dikarenakan rasanya yang enak diperingkat pertama, kemudian adalah dari desain kemasannya sedangkan pengaruh media, harga dan merk kurang berpengaruh terhadap tingkat keputusan pembelian responden.

4. Responden menyukai produk cokelat pasaran Silverqueen diperingkat pertama, kemudian Cadbury dan selanjutnya adalah produk cokelat lokal.

5. Untuk atribut bentuk desain fungsionalitas kemasan cokelat yang diharapkan konsumen adalah lebih pada desainnya harus yang dapat menarik perhatian daripada mudah diletakkan dan nyaman digenggam.

6. Untuk atribut material desain fungsionalitas kemasan cokelat yang diharapkan konsumen adalah lebih pada yang bersifat ramah untuk lingkungan.
7. Untuk atribut ukuran desain fungsionalitas kemasan cokelat yang diharapkan konsumen adalah lebih pada ukuran sedang 500 gr atau yang sesuai dengan kebutuhan konsumen.

\section{Uji desain dengan bantuan teknologi (RDE)}

Setelah elemen desain terpilih berdasarkan penilaian responden, selanjutnya peneliti mencoba mewujudkannya dengan dengan menggunakan komputerisasi (RDE), elemen terpilih tersebut diaplikasikan kedalam kesatuan wujud fungsionalitas sebuah desain kemasan yang baru. Peneliti menggunakan program 3ds max untuk melihat hasil wujud dari kemasan (Gambar 5).

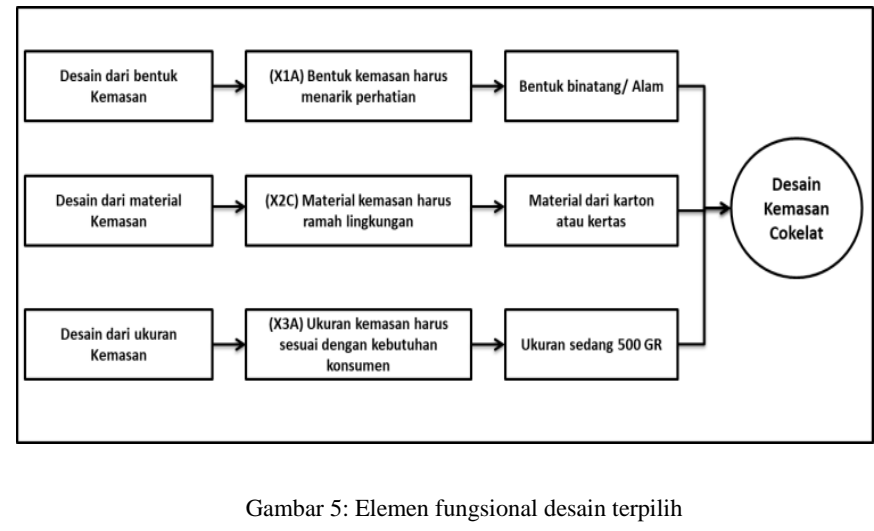

Tabele 3 menjelaskan proses pembuatan kemasan secara RDE yang meliputi 4 (empat) buah proses secara berurutan.

\begin{tabular}{|c|c|c|}
\hline No & Proses 1 & Proses 2 \\
\hline 1 & $\begin{array}{l}\text { Peneliti membuat } \\
\text { mengumpulkan semua } \\
\text { data yang dapat } \\
\text { diaplikasikan kedalam } \\
\text { desain seperti data dari } \\
\text { hasil FGD responden } \\
\text { terkait elemen desain } \\
\text { fungsional terpilih }\end{array}$ & $\begin{array}{l}\text { Peneliti mencoba } \\
\text { membuat sketsa dasar } \\
\text { dengan beberapa } \\
\text { alternative untuk } \\
\text { menghasilkan desain } \\
\text { kemasan mula-mula } \\
\text { berdasarkan elemen } \\
\text { desain terpilih }\end{array}$ \\
\hline & Proses 3 & Proses 4 \\
\hline 2 & $\begin{array}{l}\text { Setelah terpilih dari } \\
\text { sketsa desain kemasan, } \\
\text { peneliti mencoba } \\
\text { mengaplikasikannya } \\
\text { secara komputerisasi } \\
\text { (RDE), disini peneliti } \\
\text { menggunakan program } \\
\text { 3DSMAX }\end{array}$ & $\begin{array}{l}\text { Desain tercipta dan } \\
\text { peneliti melakukan } \\
\text { proses finishing untuk } \\
\text { merapikan tampilan dan } \\
\text { juga dapat dilanjutkan } \\
\text { untuk membuat model } \\
\text { atu prototipe }\end{array}$ \\
\hline
\end{tabular}

Tabel 4 menunjukkan hasil desain yang diperoleh dari studi mengenai peran elemen fungsional desain pada kemasan cokelat. 


\section{Yosef Richo}

Desain Produk Kemasan Cokelat dengan Menggunakan Peran Elemen Fungsional Desain

\begin{tabular}{l} 
Tabel 4: Hasil desain \\
\begin{tabular}{|l|l|l|}
\hline No & \multicolumn{1}{|c|}{ Keterangan } & $\begin{array}{l}\text { Gambar kemasan } \\
\text { cokelat beserta desain } \\
\text { bentuk cokelat yang } \\
\text { mengikuti bentuk alam } \\
\text { atau binatang agar dapat } \\
\text { menarik perhatian } \\
\text { konsumen. }\end{array}$ \\
\hline 2 & $\begin{array}{l}\text { Bentuk cokelat } \\
\text { berbentuk macam- } \\
\text { macam binatang yang } \\
\text { lucu }\end{array}$ & $\begin{array}{l}\text { Gambar } \\
\text { ukuran sedang 500 gr } \\
\text { yang bisa memuat } \\
\text { beberapa cokelat } \\
\text { sekaligus. }\end{array}$ \\
\hline $\begin{array}{l}\text { Kemasan terbuat dari } \\
\text { karton daur ulang } \\
\text { sehingga ramah } \\
\text { lingkungan, kuat dan } \\
\text { ahan lama. }\end{array}$
\end{tabular} \\
\hline
\end{tabular}

\section{KESIMPULAN}

Penelitian ini adalah penelitian yang bertujuan untuk mendapatkan final desain dari pendapat konsumen atau responden sehingga diharapkan desain yang didapatkan adalah sesuai dengan keinginan dari konsumen, Focus Group Discussion (FGD) dilakukan dalam penelitian ini untuk menfokuskan pada responden sesuai kriteria yang diharapkan dan mempermudah mendapatkan data. Hasil desain penelitian ini perlu dikaji lebih lanjut lagi kedepan terutama terkait pengujian kembali hasil kemasan kepada konsumen apakah sudah benar-benar dapat mempengaruhi niat pembelian. Selanjutnya adalah kajian tentang kesesuaian dengan aspek produksi kemasan apakah dapat benar-benar diproduksi secara massal. Penelitian juga nantinya dapat ditambahkan dan disatukan dengan hasil atribut elemen desain lain yang tidak dibahas dalam penelitian ini seperti elemen visual sehingga cakupan elemen desain kemasan dapat teraplikasikan lebih luas lagi kedalam sebuah desain.

\section{DAFTAR PUSTAKA}

[1] Cahyorini and Rusfian. 2011. The Effect of Packaging Design on Impulsive Buying. Journal of Administrative Science \& Organization, January 2011, page 11-21.

[2] Sri Julianti. 2015. The Art Of Packaging. Penerbit PT Gramedia Pustaka Utama. Jakarta.

[3] Kuvykaite, Dovaliene and Navickiene. 2008. Impact of Package Elements on Consumer's Puchase Decision. Journal Economics and Management

[4] Aaron and Betty Bugusu. 2010. Innovative Food Packaging Solutions. Journal of Food Science. Vol. 73, Nr. 8.

[5] Ulrich R.Orth and Keven Malkewitz. 2008. Holistic Package Design and Consumer Brand Impression. Journal of Marketing Vol. 72, page 64-81

[6] Sultan Faisal. 2016.The role of packaging found to have the significant role in affecting customer buying behavior.International Journal of Scientific and Research Publications, Volume 6, Issue 4.

[7] Alex Goftman and Howard R. Moskowitz. 2010. Accelerating Structured Consumer-Driven Package Design. Journal of Consumer Marketing p 157-168.

[8] William Boateng. 2012.Evaluating the Efficacy of Focus Group Discussion (FGD) in Qualitative Social Research. International Journal of Business and Social ScienceVol. 3 No. 7

[9] Hair, Black, and Babin. 2009.Multivariet Data Analysis. Book statistic Seventh Edition. 